\title{
As contrarreformas na política de saúde do governo Temer
}

\author{
Maria Inês Souza Bravo ${ }^{1}$ \\ Elaine Junger Pelaez ${ }^{2}$ \\ Wladimir Nunes Pinheiro ${ }^{3}$
}

\section{Resumo:}

O presente artigo pretende abordar as mudanças na política de saúde ocorridas no governo Temer, com destaque às contrarreformas que vêm sendo implementadas desde o seu início. Objetiva apontar as disputas entre projetos de saúde e os interesses privilegiados com tais medidas. Foram analisados documentos, Portarias governamentais, reportagens de jornais e revistas sobre a política de saúde no atual governo. Por fim, são apontadas a caracterização do atual governo e estratégias de mobilização e resistência às contrarreformas na saúde.

Palavras Chaves: Governo Temer - Política de Saúde - Contrarreformas

\begin{abstract}
:
The present article intends to address the changes in the health policy occurred in the Temer government, with emphasis on the counter - reforms that have been implemented since its inception. It aims to point out disputes between health projects and privileged interests with such measures. Documents, government ordinances, newspaper and magazine reports on health policy in the current government were analyzed. Finally, it is pointed out the characterization of the current government and strategies of mobilization and resistance to counterreforms in health.
\end{abstract}

Keywords: Government Temer - Health Policy - Counter Reforms.

\footnotetext{
${ }^{1}$ Assistente Social, doutora em Serviço Social (PUC/SP) e pós-doutora em Serviço Social pela UFRJ, professora aposentada da UFRJ, professora associada da Faculdade de Serviço Social da Universidade do Estado do Rio de Janeiro (UERJ), coordenadora dos projetos "Políticas Públicas de Saúde: o potencial dos movimentos sociais e dos conselhos do Rio de Janeiro" e "Saúde, Serviço Social, Movimentos Sociais e Conselhos", financiados pelo CNPq e UERJ. Integrante do Fórum de Saúde do Rio de Janeiro e da Frente Nacional contra a Privatização da Saúde (e-mail: mibravo@uol.com.br).

${ }^{2}$ Assistente Social Instituto Nacional de Traumatologia e Ortopedia - INTO/Ministério da Saúde, Especialista em Saúde Pública (ENSP/FIOCRUZ) e Especialista em Avaliação em Saúde (ENSP/FIOCRUZ). Membro da diretoria do Conselho Federal de Serviço Social - CFESS - Gestão 2017-2020 "É de Batalhas que se vive a vida". Integrante do Fórum de Saúde do Rio de Janeiro e da Frente Nacional contra a Privatização da Saúde (e-mail: elainejpelaez@yahoo.com.br).

${ }^{3}$ Médico, professor do Departamento de Promoção da Saúde do Centro de Ciências Médicas da Universidade Federal da Paraíba. Integrante do Fórum de Saúde da Paraíba e da Frente Nacional contra a Privatização da Saúde (e-mail: wladnp@uol.com.br).
} 


\section{Apresentação}

O texto ao abordar as mudanças na política de saúde ocorridas no governo Temer, vai ressaltar que a atual configuração do Sistema Único de Saúde (SUS) é fruto das disputas entre projetos distintos e antagônicos existentes na sociedade brasileira para a área da saúde desde antes da Constituição de 1988.

Dentre esses, destaca-se o Projeto da Reforma Sanitária, construído a partir de meados dos anos 1970, com base nas lutas populares e sindicais pelo direito à saúde e nos posicionamentos críticos às limitações do modelo médico assistencial previdenciário, vigente no Brasil até o advento do SUS, por parte das universidades e entidades que congregavam o pensamento sanitário brasileiro (Associação Brasileira de Saúde Coletiva - ABRASCO e Centro Brasileiro de Estudos em Saúde - CEBES). Foi influenciado, entre outros, pelo Movimento da Reforma Sanitária Italiana, e pelo novo pensamento em saúde latino americano, que, por essa época, discutia e formulava um novo referencial para a explicação do processo saúde-doença, o modelo da determinação social. Para o mesmo, a saúde possui um caráter universal, configurando-se como direito social, a ser garantido por políticas públicas intersetoriais e ações em saúde com qualidade, respondendo a todas as necessidades da população, executadas, primordialmente, pelo próprio Estado (BRAVO, 1996).

O Projeto Privatista, que adquire robustez no período da ditadura civil militar iniciada em 1964, tem sua lógica orientada pelas regras de mercado e fundamentada na exploração da doença como sua principal fonte de lucros. Representando os interesses do setor privado nacional na área de saúde, possui fortes vínculos com o capital internacional, através de sua relação com o complexo financeiro industrial médico, hospitalar, farmacêutico e de insumos. Além da exploração da população que faz uso de serviços através da compra direta de consultas, procedimentos e exames, ou utilização de planos e convênios privados, a partir da década de 1990 passa a atuar também na execução de ações de saúde, substituindo o Estado no provimento de serviços através dos chamados "Novos Modelos de Gestão" (Organizações Sociais, Organizações da Sociedade Civil de Interesse Público, Parcerias Público-privadas e Empresa Brasileira de Serviços Hospitalares, entre outros) que, associado a subvenções e isenções fiscais, avança sob o fundo público como uma nova forma de garantia de acumulação de capital. (BRAVO e MATOS, 2004).

Pode ser apontado ainda um terceiro projeto, o da Reforma Sanitária Flexibilizada, que adquire contornos próprios em meio às contradições inerentes à implementação do SUS no contexto da reconfiguração do Estado brasileiro e progressivo desmonte e subfinanciamento das políticas públicas, atendendo às exigências da política macroeconômica adotada no país 
pautada pelo Consenso de Washington (1989). Esse projeto do "SUS possível” é pautado por arranjos institucionais, mecanismos gerenciais e responsabilização dos profissionais para a adequação da política de saúde às exigências de uma política de rebaixamento da proposta inicial do Projeto da Reforma Sanitária, mesmo que isso envolva concessões que contrariam os interesses dos trabalhadores e o pleno usufruto do direito à saúde. Este projeto se consolida nos governos petistas (BRAVO, 2013).

As disputas existentes entre esses projetos inscrevem-se no processo de desenvolvimento do próprio sistema capitalista em sua fase neoliberal, com redução do papel do Estado na sociedade, diminuição de direitos para a classe trabalhadora, políticas públicas compensatórias focalizadas para grupos mais vulneráveis e participação cada vez maior do mercado em todos os aspectos da vida social.

À contrarreforma do Estado, realizada no governo Fernando Henrique Cardoso, seguiu-se uma série de medidas adotadas também pelos governos do Partido dos Trabalhadores, que não romperam com essa lógica, apesar dos resultados positivos de algumas políticas sobre os indicadores sociais, cumprindo um papel funcional ao capitalismo no Brasil. As políticas sociais, apesar de algumas inovações, sofreram influência da agenda da estabilidade fiscal e, consequentemente, os investimentos foram muito reduzidos, não apontando na direção de outro projeto para o país.

Na saúde não foi diferente. A análise que se faz após os governos petistas é que a disputa entre esses projetos na saúde continuou. Algumas propostas procuraram enfatizar a Reforma Sanitária, mas não houve vontade política e financiamento para viabilizá-las. O que se percebe é uma continuidade das políticas focais, a falta de democratização do acesso, a não viabilização da Seguridade Social, a articulação com o mercado e a manutenção da política de ajuste fiscal. Com relação ao movimento sanitário, algumas entidades históricas, a partir de 2008, tem procurado debater alguns eixos temáticos que considera importantes para a atualização da agenda da Reforma Sanitária brasileira, entretanto flexibilizando seu referencial teórico que vai ser orientado pela socialdemocracia, não tendo como preocupação a superação do capitalismo, concepção anterior que tinha como horizonte a emancipação humana, que só seria alcançada com o socialismo. (BRAVO e MENEZES, 2013)

Com o advento do governo Temer, é flagrante a aceleração e a intensificação das políticas que contribuem com o desmonte do Estado brasileiro, configurando uma nova fase de contrarreformas estruturais que atacam os direitos dos trabalhadores, como pode ser observado nos documentos "Agenda Brasil", "Uma Ponte para o Futuro" e "Travessia Social" que serão abordados posteriormente.. Na saúde não será diferente. 
Este artigo está organizado em dois itens centrais. O primeiro vai ressaltar brevemente as questões vivenciadas pela saúde a partir dos anos 1990, a conjuntura do governo Temer e os documentos que fundamentaram sua ação, ressaltando a saúde. O segundo item vai caracterizar as ações de desmonte na saúde ocorridas e em andamento durante esse governo nos anos de 2016 e 2017. Nas considerações finais, serão apresentadas as lutas e os movimentos de resistência a esse processo de desmonte do direito à saúde e algumas propostas.

\section{Impasses vividos pela Saúde a partir dos anos 1990 e a conjuntura do governo Temer}

Os processos de privatização e de retrocessos na política de saúde não começam no Governo Temer. Se inserem no quadro social, econômico e político sintonizado com processos observados mundialmente e se concretiza com as mediações relacionadas às condições de inserção do Brasil no cenário político-econômico mundial e ao seu particular desenvolvimento histórico.

No Brasil, desde os anos 1990, vivencia-se o processo de contrarreforma do Estado (BEHRING, 2003), resultando em inflexões no campo das políticas sociais que atingem diretamente a saúde pública e o conjunto da Seguridade Social, em consonância com as orientações de mudanças no mundo do trabalho, por meio da reestruturação produtiva (HARVEY, 1993) e de redefiniç̧ão das funções e responsabilidades do Estado com vistas à inserção do Brasil na economia mundializada (CHESNAIS, 1996).

No contexto de crise estrutural do capital, a saúde tem sido um espaço de grande interesse de grupos econômicos em sua busca por lucros e em seu movimento para impor a lógica privada nos espaços públicos. Nesse processo, o caráter público e universal da saúde, tão caro ao Movimento de Reforma Sanitária e aos lutadores da saúde, é ameaçado.

Tem-se, desde os anos 1990, o avanço do Projeto de Saúde Privatista, diametralmente oposto ao Projeto de Reforma Sanitária, conforme já ressaltado na apresentação deste artigo.

A eleição de membros do Partido dos Trabalhadores para o cargo máximo da república federativa no âmbito do governo federal trouxe discussões, contradições e dilemas postos desde as respectivas campanhas eleitorais e que se agudizaram no decorrer dos mandatos, na medida em que são apresentadas propostas de contrarreformas (BEHRING, 2003) e ajustes no mesmo sentido das verificadas em governos anteriores de cunho neoliberal.

As manobras parlamentares, jurídicas e midiáticas que culminaram com o afastamento de Dilma Rousseff da presidência da república, no dia 12 de maio de 2016, desnudaram as fragilidades da democracia burguesa e o esgotamento da política de conciliação de classe. Em 
seu lugar assume, de maneira ilegítima, Michel Temer, representando os setores mais atrasados, conservadores e reacionários da sociedade brasileira.

O governo ilegítimo de Temer trata-se de uma restauração conservadora de um projeto político ultra neoliberal, assumidamente pró-capital, que visa resolver os impasses de acumulação e favorecer os interesses da classe dominante do país e aprofundar sua dependência junto ao capital internacional.

Assim, o peso da crise da acumulação é transferido para os trabalhadores. Nesta direção, tem-se o comprometimento de seus direitos através de propostas de contrarreformas (Trabalhista, da Previdência Social, Terceirização Irrestrita, Novo Regime Fiscal - que congela por vinte anos os gastos públicos, entre outras).

O grande responsável pelo desequilíbrio das contas públicas não foi e não são as políticas sociais, mas sim a dívida pública, nunca auditada e que, em 2015, consumiu 42,43\% do orçamento da união para pagamento de juros e amortização da dívida e somente 4,4\% para a saúde (FATORELLI; ÁVILA; COLARES, 2016 ).

Segundo BRAZ (2017), o consenso burguês está na necessidade de acelerar contrarreformas profundas que atendam a quatro objetivos centrais:

- Recolocar o Brasil (e a América Latina) na área de influência prioritária dos EUA no sentido de retomada da sua dominância imperialista em nosso subcontinente;

- Reduzir os custos do trabalho no país e aumentar a produtividade média do trabalho com base em novas formas de combinação de mais-valia relativa (incremento tecnológico para reduzir trabalho necessário e baratear a reprodução social da força de trabalho) e mais-valia absoluta (sobretudo, via flexibilização das relações trabalhistas com vistas a atacar as formas de proteção social do trabalhador);

- Implementar uma cruzada conservadora e reacionária contra os avanços sociais no campo das "minorias" como forma de promover um retrocesso cultural e ideológico no país;

- Readequar as políticas sociais a um novo programa neoliberal mais radical de modo a criar condições para um ciclo profundo de políticas de austeridade fiscal que pesarão sobre os trabalhadores.

A partir dessas observações gerais, serão apresentadas, a seguir, as considerações sobre os documentos em que se encontram sistematizadas as propostas de contrarreforma que vem sendo implementadas pelo governo Temer, destacando-se aquelas de maior impacto para as políticas de saúde.

Três documentos foram divulgados em 2015 e 2016 colocando as principais propostas para o governo formuladas pelo PMDB: "Agenda Brasil, "Uma Ponte para o Futuro" e 
"Travessia Social", que apontam para a aceleração e intensificação de medidas que contribuem com o desmonte do Estado brasileiro, configurando uma nova fase de contrarreformas estruturais que atacam os direitos dos trabalhadores.

Em agosto de 2015, o PMDB apresenta, através do presidente do Senado, a "Agenda Brasil" que, com relação à saúde, explicita as seguintes propostas: impedir o pagamento pelo SUS de tratamentos experimentais, sob o argumento de evitar a judicialização da saúde; maior desvinculação de Receitas da União; e introdução do copagamento no SUS, ou seja, começar a cobrar por consulta, exames e outros procedimentos dentro do sistema público de saúde, de acordo com a renda do cidadão. Esta última proposta foi deixada de lado pelo governo após grande repercussão negativa entre diversos movimentos sociais que lutam em defesa do SUS, apesar de poder retornar a qualquer momento.

Em outubro de 2015, é apresentado pelo PMDB o documento "Uma Ponte para o Futuro", que coloca como questões centrais: necessidade de maior ajuste fiscal para ampliar o crescimento econômico; acabar com as vinculações constitucionais, como no caso da saúde e educação; fim de todas as indexações, sejam para salários, benefícios previdenciários etc.; nova Reforma da Previdência, que amplie a idade mínima para aposentadoria; viabilizar a participação mais efetiva do setor privado na construção de infraestrutura; maior cooperação do Estado com o setor privado na abertura dos mercados externos; executar uma política de desenvolvimento centrada na iniciativa privada; estabelecer uma agenda de transparência e de avaliação de políticas públicas que permita identificação dos beneficiários e análise dos impactos dos programas. Uma consideração importante é que o documento afirma que o Brasil gasta muito com políticas públicas ao mesmo tempo em que tem resultados piores que de outros países.

Em abril de 2016, em plena discussão do impeachment, é apresentado pelo PMDB o documento "Travessia Social", expressão da política social do programa "Uma Ponte para o Futuro". De uma forma geral, tem como propostas: conter a inflação e realizar o ajuste fiscal, o que exigirá cortes nos gastos sociais; a retomada do crescimento que possibilitará a inserção das pessoas no mercado de trabalho; transferir para o setor privado tudo o que for possível; focalização das ações nos $40 \%$ mais pobres da população pobre. Destaca como papel do Estado: qualificar as pessoas para que tenham mais competitividade no mercado de trabalho. No que se refere à Educação, é ressaltada a ênfase na formação técnica. Com relação à Saúde e ao SUS, coloca como questões importantes: a ênfase no gerencialismo, considerando como problema do SUS a má gestão; a necessidade de focalização na parcela que não pode pagar planos privados de saúde; e o estímulo ao aumento de cobertura dos planos privados. 
No item a seguir, serão abordados os ataques à saúde realizados pelo governo Temer.

\section{A Saúde no governo Temer}

No governo Temer temos a aceleração dos processos de contrarreforma e a continuidade do processo de privatização "não clássica" na saúde, adensados pelo congelamento de recursos orçamentários para as políticas sociais por vinte anos, a proposição dos chamados planos de saúde acessíveis, propostas de retrocessos na política de saúde mental e de mudanças na Política Nacional de Atenção Básica - PNAB; articulação efetiva com o setor privado através da Coalizão Saúde que serão abordados a seguir. Em síntese, o Governo Temer repete na saúde a sua tática para o conjunto da gestão, que consiste no aprofundamento das contrarreformas e na aceleração do desmonte das políticas públicas e universais.

O atual governo dá continuidade ao discurso de seus antecessores, mas com maior intensidade, conforme já salientado. Desse modo, tem-se propagado um discurso sobre a "crise" na saúde e na sociedade em geral, consistindo em um discurso ideológico, algo que podemos chamar de uma "cultura política da crise" (MOTA, 1995), forjada já desde os anos 1990, que tenta fazer com que acreditemos que as propostas de ajustes e de retiradas de direitos são inevitáveis nesse contexto e que as perdas serão compartilhadas por todos. $\mathrm{Na}$ realidade, contudo, não é isso que ocorre, pois é a classe trabalhadora que está pagando o preço desta crise.

O discurso da falaciosa necessidade de redução do SUS inaugura a gestão do Ministro da Saúde Ricardo Barros, que afirma que o país não conseguirá sustentar os direitos da Constituição Federal de 1988 como o acesso universal à saúde, e será preciso repensá-los, pois não haverá capacidade financeira para suprir todas as garantias. O referido Ministro, que teve seu financiamento de campanha para deputado federal vinculado a um consórcio de planos de saúde privados ${ }^{4}$, apresenta a proposta de Planos de Saúde Populares como um dos pilares da sua gestão à frente do Ministério da Saúde.

Com esse intento, foi editada a Portaria $\mathrm{n}^{\mathrm{o}}$ 1.482, de 4 de agosto de 2016, que institui um grupo de trabalho para discutir o projeto de Plano de Saúde Acessível. O resultado das discussões realizadas por esse grupo se encontra sistematizado no ofício n ${ }^{\circ} 60$ da Secretaria de Atenção à Saúde, encaminhado à Agência Nacional de Saúde Suplementar (ANS) em 18 de janeiro de 2017, para avaliação e manifestação com relação à sua viabilidade técnica.

\footnotetext{
${ }^{4}$ O maior doador individual de campanha de Ricardo Barros para deputado federal em 2014 foi Elon Gomes de Almeida, presidente e fundador do Grupo Aliança, conforme apontado em reportagem da Carta Capital de 05/09/2016.
} 
Neste ofício, encontra-se expresso a principal motivação utilizada pelo Ministério da Saúde para a defesa desse projeto: a redução de cerca de 1,5 milhões de pessoas que deixaram de fazer usos de planos privados de saúde em 2016, devido à recessão econômica e à elevada taxa de desemprego.

Esse documento apresenta as seguintes propostas para o Plano de Saúde Acessível:

- Plano Simplificado: cobertura para atenção primária, incluindo consultas nas especialidades previstas no Conselho Federal de Medicina - CFM e serviços auxiliares de diagnóstico e terapias de baixa e média complexidade. Nessa proposta não há previsão para exames ambulatoriais de alta complexidade, para internação, terapias e exames de alta complexidade, atendimento de urgência e emergência e hospital dia.

- Plano Ambulatorial + hospitalar: cobertura de toda atenção primária, atenção especializada, de média e alta complexidade. O paciente passaria obrigatoriamente por uma prévia avaliação realizada por médico da família escolhido pelo beneficiário. Caberá a esse médico encaminhar o paciente para a rede especializada, caso julgue necessário. Havendo indicação para atendimento hospitalar, o beneficiário poderá ser encaminhado para uma segunda avaliação médica que reafirme a necessidade para o encaminhamento do procedimento. Vale ressaltar que a cobertura do plano está adaptada à disponibilidade de infraestrutura no município e à capacidade operacional da rede particular. bem como a criação de dupla autorização pela operadora, o que é vedado pela legislação., dificultando o acesso após uma única autorização.

- Plano em Regime Misto de Pagamento: oferece serviço por intermédio de contraprestação mensal para cobertura de serviços hospitalares, terapias de alta complexidade e medicina preventiva, bem como, quando necessário, atendimento ambulatorial. Fica sob a responsabilidade do beneficiário o pagamento do procedimento, de acordo com valores previstos em contrato. Os modelos de pré e pós-pagamento serão acordados, assegurando o Rol de Procedimentos da ANS. Nessa modalidade as operadoras seriam livres para cobrar um fator moderador (coparticipação) de $50 \%$.

Em termos de avaliação e crítica aos Planos de Saúde Acessíveis, várias entidades apresentaram posicionamentos contrários. O Conselho Nacional de Saúde, em 10 de março de 2017, apresentou uma Moção de Repúdio à proposta, enfatizando que a mesma subverte o papel do Estado e representa grave retrocesso, apresentando muitas restrições de cobertura, o que fere o princípio da integralidade da assistência; destaca também a diminuição da competência regulatória da ANS. A ASSETANS (Associação dos Servidores e demais Trabalhadores da ANS), em assembleia realizada em 05 de setembro de 2017, aprova um posicionamento contrário aos Planos de Saúde Acessíveis, destacando que suas características 
limitam as coberturas garantidas pela Lei 9.656 e sua regulamentação, contrariando o princípio da integralidade da atenção em cada segmento hoje existente; considera que fatores acima de $30 \%$ são considerados restritores severos ao acesso aos serviços, pois a proposta enfatiza que o copagamento para acesso aos mesmos está previsto em 50\%. Ressalta também que os serviços oferecidos serão parcelados, de baixa qualidade e jogando para o sistema público os procedimentos de alto custo.

Com relação ao financiamento, uma medida drástica do governo foi o congelamento dos gastos, através da PEC 95/2016, cujos impactos para a saúde são enormes. O estudo realizado pelo IPEA por meio da Nota Técnica 28, elaborada por Fabiola Vieira e Rodrigo Benevides (2016), apresenta algumas questões seríssimas com relação ao orçamento.

Uma dessas questões é a perda de recursos federais destinados ao SUS estimada em $\mathrm{R} \$ 654$ bilhões de reais nesse período de 20 anos, em um cenário conservador (crescimento médio do PIB de $2 \%$ ao ano). Ao utilizar uma estimativa de crescimento maior ( $3 \%$ ao ano), a estimativa chega a R\$ 1 trilhão. Ou seja: ao comparar a regra da PEC com a atual, quanto mais a economia brasileira crescer nesse período, maior a perda de recursos para a Saúde.

Os pesquisadores do IPEA ainda chamam a atenção para o fato de que a população de idosos no Brasil deve dobrar entre 2016 e 2036, de 24,9 milhões para 48,9 milhões (12,1\% a 21,5\% do total). O impacto dessa mudança do perfil demográfico para o SUS é evidente: idosos adoecem mais e procuram mais os serviços de saúde, demandando também mais estrutura e insumos.

Com relação à revisão da Política Nacional de Atenção Básica, pactuada na Reunião da CIT (Comissão Intergestora Tripartite, composta por Ministério da Saúde, Conselho Nacional dos Secretários de Saúde-CONASS e Conselhos Nacionais dos Secretários Municipais de Saúde - CONASEMS) em 31/08/2017, ressalta-se que a mesma não foi analisada no Conselho Nacional de Saúde e não foi discutida junto à sociedade, restringindo esse debate a uma consulta pública por meio eletrônico, realizada em um curtíssimo espaço de tempo.. Apesar do texto afirmar que a Saúde da Família continua como a estratégia prioritária para a expansão e consolidação da Atenção Básica no Brasil, o mesmo rompe com sua centralidade e institui formas de financiamento para outros arranjos assistenciais que não contemplem equipes multiprofissionais com a presença de agentes comunitários de saúde (ACS), possibilitando a organização da Atenção Básica com base em princípios opostos àqueles norteadores da Atenção Primária à Saúde (APS). Também causa estranheza a referência à diferenciação de ações e serviços "essenciais" e "ampliados" a serem executados na Atenção Básica, o que pode configurar restrições ao acesso à assistência, legitimando sua 
configuração como uma política focalista e restrita a populações mais vulneráveis ou agravos mais comuns, limitando-se a oferta do "mínimo do mínimo" no que consta aos serviços oferecidos à população. Outra questão à política aprovada refere-se à redução da carga horária da equipe de 40 horas, podendo ser de 10 horas.

Com relação à Política de Saúde Mental, têm sido propostas alterações avaliadas como ameaça às conquistas da Reforma Psiquiátrica no país. Por meio da Portaria 3.588/2017, o atual Governo engendrou mudanças na Rede de Atenção Psicossocial (RAPS) que apontam para o fortalecimento das internações em hospitais psiquiátricos e criação de leitos em hospitais gerais e serviços ambulatoriais, por meio de ampliação de recursos para tais fins. A proposta foi aprovada pela CIT em 21 de dezembro de 2017, sem que pesquisadores e representantes do controle social tivessem direito a fala e sem consulta à sociedade.

Tal política é alvo de críticas em face da ausência de participação social em sua formulação e por estar na contramão do modelo de atenção em saúde mental que preconiza a desinstitucionalização e reabilitação psicossocial das pessoas com transtornos mentais, como consubstanciado na Lei 10.216/01. O Movimento Nacional de Luta Antimanicomial repudia tais propostas por compreender que representa retrocesso na implantação da rede de atenção psicossocial territorializada, de base comunitária e construída com participação dos movimentos sociais da luta antimanicomial e do controle social, conforme consta na Nota de Repúdio contra o desmonte da Política de Saúde Mental, de 11 de dezembro 2017. A Associação Brasileira de Saúde Mental - ABRASME também apresenta posição contrária, por entender que a nova política traz de volta a perspectiva manicomial e secundariza o investimento em serviços de base territorial e comunitária, de acordo com reportagem do Viomundo de 15/02/2018.

Outra característica do governo Temer, conforme já sinalizado, é a articulação efetiva com o setor empresarial de saúde que pode ser observada nas propostas apresentadas pelo governo de modificação da política de saúde. A medida mais importante do setor privado, até o momento, foi a elaboração do documento Coalizão Saúde Brasil: uma agenda para transformar o sistema de saúde, divulgado em 2017. Este documento foi elaborado pelo Instituto Coalizão Brasil, formado por representantes da cadeia produtiva do setor saúde e que tem como objetivo enfrentar e construir um novo sistema de saúde para o Brasil.

O documento final foi elaborado por 80 especialistas e 30 instituições. A tese defendida pelo grupo é a de que os setores público e privado precisam construir uma rede integrada de cuidados contínuos. A integração pressupõe mais participação da iniciativa privada na gestão dos serviços, através de um novo modelo de governança. Há preocupação 
com a participação de empresários na difusão de ideias e disputa político-ideológica, bem como com a possível apropriação de conceitos do SUS de modo a atribuir outros significados.

O início deste processo data de 2014, primeiramente com a participação da Associação Nacional de Hospitais Privados em articulação com a FIESP (Federação das Indústrias do Estado de São Paulo). Em julho de 2014 surge o Coalizão Saúde, lançado na Faculdade de Medicina da USP e que reúne parte significativa da cadeia produtiva da saúde. Avalia-se que o objetivo da criação desta articulação foi influenciar nas eleições (REVISTA POLI, n 48, nov/dez/2016).

A partir de 2016 ampliam-se o número de associados, totalizando vinte e quatro, a saber: Jonhson \& Johnson; Qualicorp e Unimed Brasil; Federação Nacional de Saúde Suplementar (Fenasaude); Associação da Indústria Farmacêutica de Pesquisa (Interfarma); Confederação Nacional de Saúde (CNS) e Confederação das Santas Casas, Hospitais e Entidades Filantrópicas. A agenda prioritária do grupo pauta-se nas seguintes proposições: as soluções para os sistemas de saúde público e privado ou simplesmente Sistema de Saúde Brasileiro (e não mais SUS) passam por fortalecer os mecanismos de livre mercado, como as parcerias público-privadas, as OSs e um novo modelo de governança que amplie a participação dos prestadores privados de assistência à saúde na definição das políticas de saúde. Como propostas para a governança apresenta novas modalidades de Conselho e Conferências, que consiste em Conselhos formados por especialistas e ligados ao gabinete dos prefeitos, o que consideram mais estratégicos que os Conselhos Municipais de Saúde. Nacionalmente deveria ser criado um Conselho Executivo, também formado por especialistas, com o poder de definir estratégias (Ibid). Em junho de 2016 estas propostas foram apresentadas ao Senado Brasileiro em Seminário realizado em parceria com o Conselho Nacional de Justiça (CNJ) e a Associação Médica Brasileira (AMB) e em agosto de 2016 ocorreu uma audiência sobre o tema com o presidente Michel Temer.

Em 2017 o grupo lança o documento intitulado "Coalizão Saúde Brasil: uma agenda para transformar o sistema de saúde", com diagnóstico e propostas mais detalhadas. No diagnóstico, explicita aumento da carga de doenças; falta de promoção e prevenção; alta expectativa e pouca informação do paciente; governança pouco efetiva; alocação de recursos inadequada; práticas de gestão ineficientes; baixo foco no desfecho; uso de dados e inovação limitados; problemas de sustentabilidade. Com relação às iniciativas a serem priorizadas, ressaltam: estimular mudança cultural para a promoção; fortalecer a atenção primária; ampliar acesso a medicamentos; estimular modelos inovadores de atenção; construir agenda nacional para inovação; estimular modelos assistenciais com foco no idoso e no doente crônico; 
estabelecer protocolos clínicos de referência nacional; discutir sobre os diferentes modelos de pagamentos; divulgar os dados nos sistemas público e privado; criar o prontuário eletrônico; reorganizar o sistema de redes de atenção (COALIZÃO SAÚDE BRASIL, 2017).

Outras medidas do Ministério da Saúde neste governo são as propostas de Alterações na Lei dos Planos de Saúde. Em setembro de 2017, o relator da Comissão Especial sobre Planos de Saúde da Câmara dos Deputados, Rogério Marinho (PSDB/RN), apresentou os principais pontos que pretende inserir no seu relatório, quais sejam:

- Revogação da Lei dos Planos de Saúde - É nítida a intenção do relator de revogar a Lei 9656/1998 para estabelecer um novo marco legal que prejudicará os usuários dos planos e beneficiará as operadoras;

- Segmentação de Cobertura Assistencial, na medida em que propõe que ao contratar um plano de saúde, o usuário, família ou empresa escolheria quais procedimentos quer incluir no plano, quais doenças seriam cobertas e, com isto, pagaria menos;

- Reajuste após 60 anos de idade, o que denota a intenção de alterar o Estatuto do Idoso, que hoje proíbe reajuste após 60 anos. Na prática, a possibilidade de aplicação de reajustes após 60 anos significará a expulsão dos idosos dos planos de saúde;

- Diminuição do valor do Ressarcimento ao SUS, o que acarreta perda de recursos pelo SUS bem como, Redução do Valor de Multas aplicadas pela ANS contra planos de saúde.

A gravidade dos retrocessos nas mudanças anunciadas soma-se a inexplicável tramitação destas medidas em regime de urgência.

No item a seguir vai-se ressaltar algumas propostas significativas vindas dos movimentos de luta e resistência na saúde.

\section{Considerações Finais}

Atualmente, discutir a saúde - entendida como determinada pelas condições de vida e trabalho, direito de todos e dever do Estado - como uma pauta expressiva no cenário político nacional é um desafio que está longe de ser simples ou fácil. Avançar no sentido de propostas convergentes com os princípios do SUS e, mais que isso, da Reforma Sanitária dos anos 1970/80, requer a retomada dos seus princípios e bandeiras, da organização e aglutinação das massas em torno das questões sanitárias, semelhante ao observado a partir do período da redemocratização, sem desconsiderar as singularidades do atual momento histórico. Impõe, ainda, a explicitação dos dissensos presentes no Movimento Sanitário desde aquele período, a análise do que é necessário avançar e a discussão das estratégias, táticas e aliados. 
Merece atenção o fato de que as tarefas postas têm como cenário da sua concretização uma conjuntura distinta daquela verificada nos anos 1980, com modificações no mundo do trabalho que têm repercussões na organização e luta social, as quais resultam em fragmentação e setorialização de reivindicações dirigidas isoladamente. A forma de atuação das entidades representativas dos trabalhadores da saúde, sejam conselhos ou sindicatos, não estão alheias a tais transformações.

Trata-se de retomar a capacidade de organização e de luta com vistas à resistência contra as propostas de retirada de direitos na saúde e em outras políticas sociais, no sentido de impedir a flexibilização e/ou desmonte do marco legal constitucional e das legislações complementares que se seguiram. A inscrição de um texto constitucional, como o de 1988, não significa a perpetuação ou materialização imediata deste direito na realidade, pois o acesso dos usuários das políticas sociais é determinado tanto pela legislação vigente quanto por processos sociais inscritos na realidade contraditória e submetidos à correlação de forças entre as classes. Esse reconhecimento, contudo, não invalida nem tampouco diminui o valor das conquistas anteriores. As vitórias registradas nos processos em curso nos anos 1980, longe de encerrar as lutas, as realimentam, tanto pela necessária mobilização em prol da materialização real dos direitos assegurados constitucionalmente quanto pela constante organização e luta frente às propostas que retiram direitos, na perspectiva do fortalecimento da resistência conjunta dos trabalhadores e da ultrapassagem do corporativismo e fragmentação das reivindicações e pautas políticas.

Continuam atuais as formulações de Berlinguer (1987) intelectual da Reforma Sanitária italiana que foi inspiradora da Reforma Sanitária Brasileira. É fundamental o seu debate sobre a necessidade de "politização da saúde com o objetivo de aprofundar a consciência sanitária". O que o autor denomina de "consciência sanitária" consiste na ampliação do conhecimento da população sobre saúde e os seus determinantes sociais, mas também e, sobretudo, a ampliação das mobilizações e da ação coletiva voltada para a mudança desses determinantes estruturais, ou seja, da estrutura social e das relações sociais que produzem desigualdades e condições de vida e trabalho adversas que vão na contramão da produção de saúde em sua concepção ampliada.

As ações no sentido da mercantilização da Política de Saúde, todas as dificuldades de efetivação do SUS e as propostas de retirada dos direitos sociais em geral e do direito à saúde em específico resultaram, de forma dialética, no surgimento de novos mecanismos de lutas, como os Fóruns de Saúde e a Frente Nacional Contra a Privatização da Saúde. Trata-se de uma luta que é fundamentalmente contra as relações sociais capitalistas que reproduzem a 
desigualdade social e a exploração dos trabalhadores e estão na raiz da determinação social da saúde e da doença.

A Frente Nacional Contra a Privatização da Saúde foi criada em 2010 e integra diversas organizações, movimentos sociais e militantes da área saúde. É uma frente de esquerda, suprapartidária e antecapitalista. Desde sua criação vem se empenhando em um esforço coletivo para articular as diversas lutas em defesa do SUS de caráter público, $100 \%$ estatal e de qualidade; contra os processos de privatização com que o sistema de saúde brasileiro vem passando; e a favor de melhorias das precárias condições salariais e de trabalhos em que se encontram os diversos profissionais de saúde.

Nesse sentido, têm sido construídas reflexões e propostas, em termos de referenciais e de lutas para nortear as ações e que constituem numa agenda política, procurando articular a luta por saúde a construção de um novo projeto societário. Como síntese das propostas apresentadas pela Frente Nacional contra a Privatização da Saúde ressalta-se ${ }^{5}$ :

- Sistema de Saúde público, $100 \%$ estatal, universal e de qualidade, sob a administração direta do Estado e contra toda forma de privatização da saúde;

- Revogação das Leis que criaram as Organizações Sociais, Fundações Estatais de Direito Privado, EBSERH e Parcerias Público-privadas e retomada da gestão pública estatal bem como auditoria e devolução dos repasses públicos pelas Organizações Sociais;

- Pela eliminação dos limites da Lei de Responsabilidade Fiscal no que diz respeito à limitação de gastos com pessoal na área de saúde que podem prejudicar a execução da prestação de serviços à população

- Reajustes salariais dignos e política de valorização do servidor público, isonomia salarial, estabilidade no trabalho e Planos de Cargos, Carreiras e Salários bem como melhoria das condições de trabalho e contra todas as formas de precarização do trabalho;

- Defesa da utilização de, no mínimo, 10\% do Produto Interno Bruto (PIB) para a saúde, garantindo o investimento público e o financiamento exclusivo da rede pública estatal de serviços;

- Contra a entrada de capital estrangeiro nos serviços de assistência à saúde e pela revogação do artigo no 142 da Lei no 13.097/2015;

\footnotetext{
${ }^{5}$ Na Nota da Frente Nacional contra a Privatização da Saúde: "O ilegítimo governo Temer e os ataques ao Sistema Único de Saúde", de junho de 2016 e no Relatório do Seminário da Frente Nacional ocorrido em Maceió, em 2017, encontram-se as propostas completas.
} 
- Pela Reforma Sanitária, Psiquiátrica e contra as Comunidades Terapêuticas.

\section{Referências Bibliográficas}

AGÊNCIA NACIONAL DE SAÚDE SUPLEMENTAR. Relatório Descritivo do GT de

Planos Acessíveis: relatório de consolidação das informações e contribuições ao Projeto de Plano de Saúde Acessível. Disponível em: <http://www.ans.gov.br/images/stories/noticias/pdf/VERS\%C3\%83O_FINAL_RELATORIO _DESCRITIVO_GT_ANS_PROJETO_PLANO_DE_SAUDE_ACESSIVEL_FINAL__.pdf >. Acesso em: 20 fev. 2018.

ASSOCIAÇÃO DOS SERVIDORES E DEMAIS TRABALHADORES DA ANS. Considerações iniciais da ASSETANS sobre a Proposta de Plano Acessível de Saúde. Disponível em: <http://www.assetans.org.br/social/tag/planos-acessiveis/>. Acesso em: 20 fev. 2018.

BEHRING, E. R. Brasil em Contra-Reforma: desestruturação do Estado e perda de direitos. São Paulo: Cortez, 2003.

BERLingueR, G. Medicina e Política. Tradução de Pe. Bruno Giuliani. $3^{\circ}$ ed. São Paulo: Hucitec, 1987.

BRASIL. Lei 10216, de 6 de abril de 2001. Dispõe sobre a proteção e os direitos das pessoas portadoras de transtornos mentais e redireciona o modelo assistencial em saúde mental. Disponível em http://www.planalto.gov.br/ccivil_03/leis/leis_2001/110216.htm. Acesso em: 20 fev. 2018.

. Ministério da Saúde. Portaria n. 1.482, de 4 de agosto de 2016. Institui Grupo de Trabalho para discutir projeto de Plano de Saúde Acessível. Disponível em: <http://bvsms.saude.gov.br/bvs/saudelegis/gm/2016/prt1482_04_08_2016.html> Acesso em: 20 fev. 2018.

. Ministério da Saúde. Portaria n. 2.436, de 21 de setembro de 2017. Aprova a Política Nacional de Atenção Básica, estabelecendo a revisão de diretrizes para a organização da Atenção Básica, no âmbito do Sistema Único de Saúde (SUS). Disponível em: $<$ https://www.nescon.medicina.ufmg.br/biblioteca/imagem/portaria2436.pdf >. Acesso em: 20 fev. 2018.

. Ministério da Saúde. Portaria n. 3.588, de 21 de dezembro de 2017. Altera as Portarias de Consolidação $\mathrm{n}^{\circ} 3$ e $\mathrm{n}^{\circ}$ 6, de 28 de setembro de 2017, para dispor sobre a Rede de Atenção Psicossocial, e dá outras providências. Disponível em: 
<http://www.brasilsus.com.br/images/portarias/dezembro2017/dia22/portaria3588.pdf>. Acesso em: 20 fev. 2018.

. Ministério da Saúde. Secretaria de Atenção à Saúde. Ofício nº 60-GS/SAS. Assunto: Proposta de Plano de Saúde Acessível. Disponível em: $<$ http://www.epsjv.fiocruz.br/sites/default/files/files/Proposta-de-Plano-de-SaudeAcessivel.pdf>. Acesso em: 20 fev. 2018.

. Presidência da República. Lei 9656, de 3 de junho de 1998. Dispõe sobre os planos e seguros privados de assistência à saúde. Disponível em http://www.planalto.gov.br/Ccivil_03/leis/L9656.htm. Acesso em: 20 fev. 2018.

Emenda Constitucional 95, de 15 de dezembro de 2016. Altera o Ato das Disposições Constitucionais Transitórias, para instituir o Novo Regime Fiscal, e dá outras providências. Disponível em: <http://www.planalto.gov.br/ccivil_03/constituicao/emendas/emc/emc95.htm>. Acesso em: 20 fev. 2018.

BRAVO, M. I. S. Serviço Social e Reforma Sanitária: lutas sociais e práticas profissionais. São Paulo/Rio de Janeiro: Cortez/Ed. da UFRJ, 1996. . Prefácio. In: SILVA, L. B.; RAMOS, A. (Org.). Serviço Social, Saúde e Questões Contemporâneas: reflexões críticas sobre a prática profissional. Campinas, SP: Papel Social, 2013.

.; MENEZES, J. S. B. A Política de Saúde na Atual Conjuntura: Algumas Reflexões sobre os Governos Lula e Dilma. In: . (Org.). Serviço Social, Saúde e

Questões Contemporâneas: reflexões críticas sobre a prática profissional. Campinas: Papel Social, 2013.

; MATOS, M. C. Reforma Sanitária e projeto ético-politico do Serviço Social: elementos para o debate. In: BRAVO, M. I. S. et al (Org.). Saúde e Serviço Social. São Paulo Cortez /Rio de Janeiro: UERJ, 2004.

BRAZ, M. O golpe nas ilusões democráticas e a ascensão do conservadorismo reacionário.

Revista Serviço Social \& Sociedade. São Paulo, n. 128, p. 85-103, jan./abr. 2017

CHESNAIS, F. A Mundialização do Capital. São Paulo: Xamã, 1996.

COALIZÃO SAÚDE BRASIL. Coalizão Saúde Brasil: Uma Agenda para Transformar o Sistema de Saúde. São Paulo: Coalizão Saúde Brasil, 2017.

COLLUCCI, C. Tamanho do SUS precisa ser revisto, diz novo ministro da Saúde. Folha de São Paulo, São Paulo, 17 maio 2016. Disponível em: 
<http://www1.folha.uol.com.br/cotidiano/2016/05/1771901-tamanho-do-sus-precisa-serrevisto-diz-novo-ministro-da-saude.shtml>. Acesso em: 20 fev. 2018.

FATTORELli, M. L.; ÁVILA, R.; COLARES, G. Sobraram R\$ 480 bilhões no caixa do governo em 2015. Auditoria cidadã da dívida, Brasília, DF, 2016. Disponível em: http://www.auditoriacidada.org.br/blog/2016/7/25/sobraram-r-480-bilhoes-do-caixa-dogoverno-em-2015. Acesso em: 29 set. 2016.

FRENTE NACIONAL CONTRA A PRIVATIZAÇÃO DA SAÚDE. Relatório do VII Seminário da Frente Nacional Contra a Privatização da Saúde. Disponível em: <http://www.contraprivatizacao.com.br/2018/01/relatorio-do-vii-seminario-da-frente.html>. Acesso em: 20 fev. 2018

FUndaÇÃO Ullysses GUimarãeS; PMDB. Ponte para o Futuro. Disponível em: <https://www.fundacaoulysses.org.br/blog/acervo/>. Acesso em: 20 fev. 2018.

\section{Travessia $\quad$ Social. $\quad$ Disponível}

em:

<https://www.fundacaoulysses.org.br/blog/acervo/>. Acesso em: 20 fev. 2018.

GRANEMANN, S. Sara Granemann analisa e denuncia a privatização dos hospitais universitários. 15 nov. 2012. In: Blog Esquerda Online. Disponível em <http://blog.esquerdaonline.com/?p=376>. Acesso em 30 set. 2015.

HARVEY, D. A condição pós-moderna. São Paulo: Loyola, 1993.

LEMES, C. Walter Oliveira, sobre a "nova" política de saúde mental: "Houve manobras parecidas às usadas para comprar votos no Congresso". Viomundo, São Paulo, 15 fev. 2018. Disponível em: <http://www.viomundo.com.br/denuncias/walter-oliveira-denunciamudancas-na-politica-de-saude-mental-manobras-parecidas-as-usadas-para-comprar-votosno-congresso.html>. Acesso em: 20 fev. 2018.

MARINONI, B. Sara Granemann analisa e denuncia a privatização dos hospitais universitários. Rio de Janeiro, 15 nov. 2012. Disponível em: $<\mathrm{http}: / /$ blog.esquerdaonline.com/?p=376>. Acesso em: 20 fev. 2018.

MATHIAS, M. Uma segunda alma para o SUS? Entidades criadas por empresários da saúde abrem caminho para um Sistema Único totalmente integrado e gerido pelo setor privado. Revista POLI: saúde, educação e trabalho. Rio de Janeiro, ano 9, n. 48, nov./dez. 2016. MOTA, Ana Elizabete. Cultura da crise e seguridade social: um estudo sobre as tendências da previdência e da assistência social brasileira nos anos 80 e 90. São Paulo: Cortez, 1995. MOVIMENTO NACIONAL DE LUTA ANTIMANICOMIAL. Nota de Repúdio contra o desmonte da Política de Saúde Mental. Disponível em: <http://www.cressrj.org.br/site/wp- 
content/uploads/2017/12/NOTA_DE_REPUDIO_CONTRA_O_DESMONTE_DA_SA\%C3

\%9ADE_MENTAL_MNLA.pdf>. Acesso em: 20 fev. 2018.

VERDELIO, A. Comissão do SUS aprova Política Nacional de Atenção Básica. EBC. Agência Brasil, São Paulo, 31 ago. 2017. Disponível em: $<$ http://agenciabrasil.ebc.com.br/geral/noticia/2017-08/comissao-do-sus-aprova-revisao-dapolitica-nacional-de-atencao-basica>. Acesso em: 20 fev. 2018.

VIEIRA, F. S.; BENEVIDES, R. P. S. Os impactos do novo regime fiscal para o financiamento do Sistema Único de Saúde e para a efetivação do direito à saúde no Brasil. Brasília: Ipea, 2016. (Nota Técnica, 28). 